\title{
Malignancy rate of focal thyroid incidentaloma detected by FDG PET-CT: results of a prospective cohort study
}

\author{
Philippe Thuillier, ${ }^{1,2}$, Nathalie Roudaut ${ }^{1,2}$, Geneviève Crouzeix ${ }^{1,2}$, Marie Cavarec ${ }^{2,3}$, \\ Philippe Robin ${ }^{2,3}$, Ronan Abgral2,3, Véronique Kerlan ${ }^{1,2}$ and Pierre-Yves Salaun ${ }^{2,3}$ \\ 'Department of Endocrinology, University Hospital of Brest, Brest, France \\ ${ }^{2}$ EA GETBO 3878, University Hospital of Brest, Brest, France \\ ${ }^{3}$ Department of Nuclear Medicine, University Hospital of Brest, Brest, France
}

Correspondence

should be addressed

to P Thuillier

Email

philippe.thuillier@chu-brest.fr

\begin{abstract}
Objective: To evaluate the malignancy rate of focal thyroid incidentaloma (fTI) in a population of patients undergoing a 18F-fluorodeoxyglucose positron emission tomography-computed tomography (FDG PET-CT) for a non-thyroid purpose.

Design: We conducted a prospective cohort study from January 2013 to November 2014. All consecutive patients referred for a FDG PET-CT were prospectively screened. Patients with known neoplastic thyroid disease were excluded from the analysis. All patients presenting one or more fTI and who accepted to benefit from a complementary thyroid ultrasonography (US) were included and managed according to the French endocrine society consensus. Prevalence of fTI in our population and malignancy rate was assessed. Results: During the inclusion period, 10,171 patients were referred for a FDG PET-CT in our center. Fifty-three patients presenting a known thyroid disease were excluded. Among the remaining 10,118 patients, $127(1.3 \%)$ with $131 \mathrm{fTI}$ were individualized. US could not be performed in 37 patients. The remaining 90 patients $(92 \mathrm{fTI}$ ) were explored by US \pm fine-needle aspiration biopsy (FNAB). US results demonstrated a nodule aspect in 80 cases of which 60 benefited from FNAB. Nineteen of $92 \mathrm{fTI}$ underwent surgery with 10 malignant lesions among the 60 patients performing both US and FNAB. Conclusion: The prevalence of fTI discovered on FDG PET-CT in our population was $1.3 \%$ with 10 malignant lesions among the 60 patients performing both US and FNAB.
\end{abstract}

\author{
Key Words \\ - thyroid incidentaloma \\ - positron emission \\ tomography/computed \\ tomography \\ - 18F-fluorodeoxyglucose \\ - thyroid cancer \\ - ultrasonography
}

\section{Introduction}

Thyroid incidentaloma (TI) is a thyroid lesion discovered in patients undergoing an imaging for a non-thyroid purpose. In a retrospective study, Steele and coworkers found that the prevalence of TI fortuitously highlighted during carotid duplex ultrasonography varies from $9.4 \%$ to $27.0 \%$ (1). In cervical computed tomography (CT) and magnetic resonance imaging (MRI) scans, studies show a prevalence of TI nearly to $16 \%(2,3)$. The common use of 18F-fluorodeoxyglucose (FDG) positron emission tomography-computed tomography (PET-CT) in the field of oncology leads to a whole body imaging allowing to the discovery of unexpected lesions. TI could be discovered in such situation and according to the risk of underlying cancer, explorations have to be discussed. In FDG PET-CT, TI may appear as a focal FDG uptake (fTI) or as diffuse thyroid uptake (dTI) of the thyroid parenchyma. A recent meta-analysis of thirty studies, mostly retrospective, found a prevalence of $1.6 \%$ 
and $2.1 \%$ for fTI and dTI, respectively (4). Moreover, in another meta-analysis, malignancy rate of fTI was as high as 34.6\% (IC 95\% 29.3-40.2) (5). Only few studies proposed a prospective design to investigate prevalence and malignancy rate of fTI in FDG PET-CT exams (6). In the series of Ohba and coworkers, malignancy rate was assessed in a selected population of 1501 healthy volunteers with a mean age of $43.5 \pm 9.7$ years (6). However, to our knowledge, no prospective study was conducted in an unselected population.

The objective of this prospective study was to evaluate the prevalence fTI in a large unselected population of patient referred for a FDG PET-CT and to assess its malignancy rates.

\section{Materials and methods}

\section{Population}

From January 2013 to November 2014, we screened prospectively all consecutive patients referred to the Nuclear Medicine Department of Brest University Hospital to perform a FDG PET-CT. Patients with known neoplastic thyroid disease were excluded from the analysis. fTI was defined as the presence of a focal FDG thyroid uptake (single or multiple) on FDG PET-CT higher than the adjacent thyroid parenchyma uptake. Patients showing one or more fTI were selected even if scans showed an additional dTI. Selected patients were offered to perform a cervical ultrasonography (US). All patients who consent to perform an additional US were included.

\section{Management of fTI}

Patients included were managed according to French endocrine society guidelines and explored by a neck US \pm a fine-needle aspiration biopsy (FNAB) (7). Based on the results of the investigations, patients medical care was done in compliance with current recommendations consisted with several possibilities: abstention, fTI monitoring (clinical follow-up and/or neck US \pm FNAB repetition) or surgical indication.

\section{Imaging procedures}

FDG PET-CT indication and ongoing oncologic treatments were recorded.

FDG PET-CT scan was performed on a Biograph mCT S64 (Siemens Medical, Erlangen, Germany). Patients fasted $4 \mathrm{~h}$ before PET acquisitions, and the blood glucose level had to be less than $7 \mathrm{mmol} / \mathrm{L}$ before injection of $370 \mathrm{MBq}(5 \mathrm{MBq} / \mathrm{kg})$ of FDG. For FDG PET quantification, a standardized uptake value (SUV)-based approach was used. SUV was defined as follows: SUV=tissue radioactivity concentration $(\mathrm{kBq} / \mathrm{mL}) /$ (injected dose $(\mathrm{kBq}) /$ patient weight $(\mathrm{g})$ ). Within a spherical volume of interest (VOI) drawn around fTI area, maximal SUV (SUVmax) was calculated.

Neck US was performed, using a linear transducer of $10 \mathrm{MHz}$ on a Toshiba ultrasound Xario SSA-666A, by an experienced physician (10 years) with the knowledge of FDG PET-CT results in order to locate the fTI. Thyroid parenchyma was studied (size, echogenicity and echostructure) and signs of an eventual thyroiditis were reported. Thyroid nodules were characterized according to the usual criteria (dimensions, echogenicity, echostructure, margins, presence or absence of macrocalcifiations, microcalcifications and type of vascularization: absent, peripheral or predominantly peripheral, central or predominantly central, diffuse). After initial US exploration, nodules were also classified according to 3 classifications: Kim's criteria (8), TIRADS score (9) and French endocrine society consensus of 2011 (7).

FNAB was proposed for all fTI (s) corresponding to a thyroid nodule with a size $\geq 7 \mathrm{~mm}$, in agreement with French endocrine society consensus (7). FNAB was performed with a $25 \mathrm{G}$ needle under ultrasound guidance by the same echographist. Two minimum samples were performed. A single experienced pathologist performed all cytological interpretation and results were delivered according to the Bethesda classification in 6 usual categories ( $\mathrm{I}=$ nondiagnostic; $\mathrm{II}=$ benign; $\mathrm{III}=$ atypia/follicular lesion of undetermined significance (AUS/FLUS); IV=follicular neoplasm/suspicion for a follicular neoplasm (FN/SFN); $\mathrm{V}=$ suspicious for malignancy; $\mathrm{VI}=$ malignant) (10).

\section{Follow-up}

An experienced pathologist performed histological evaluation of the fTI treated surgically. In case of histologically proven malignant pathology, pTNM staging according to WHO classification was used (11).

Prevalence of fTI in the whole population was calculated. The rate of cancer was assessed on the population showing fTI on FDG PET-CT and was defined as the number of cancer confirmed histologically or cytologically (Class VI) relative to the total number of fTI benefiting from an US + FNAB. 
To define the characteristics of malignant fTI and compare them with the benign fTI, we classified each fTI according to cytological and histological data as 'benign' or 'malignant'. In the absence of histological data, classification was done according to cytological findings, with Bethesda classification, as benign for thyroid nodules ranged 2 and malignant for thyroid nodules ranged 5 or 6 . Thyroid nodules classified 1, 3 and 4 were classified as undeterminate.

\section{Statistics}

Descriptive statistics were used to characterize the study cohort. Continuous variables were summarized as mean \pm S.D. when normally distributed or as median with interquartile range (IQR) otherwise. Categorical variables were presented as counts and percentages.

According to FES guidelines and literature data, we compared usual clinical thyroid cancer risk factors (age $>65$ years, male gender), PET-CT parameters (SUVmax median), US characteristics (4 majors malignancy criteria defined as presence of marked hypoechogenicity, irregular margins, more tall than wide dimension and presence of microcalcifications according to Kim and coworkers) and indication to a FNAB according to US classifications used in literature to describe thyroid nodule (TIRADS $\geq 4 \mathrm{~A}$, presence of at least one or more Kim criteria, presence of at least two or more criteria (hypoechogenicity, irregular margins, more tall than wide dimension, presence of microcalcifications and central vascularization) according to FES guidelines) in each benign or malignant groups $(7,8,9)$. The Fisher exact and Mann-Whitney $U$ tests were used to make comparisons between groups as appropriate.

All analyses were conducted at the 0.05 significance level using SPSS Statistics, v20 software.

All patients were then informed of the purpose of the study and provided an informed consent to participate in the study.

\section{Results}

\section{Population}

Between January 3rd, 2013, and October 30th, 2014, 10,171 FDG PET-CT were performed in the Nuclear Medicine Department of the University Hospital of Brest. Out of 10,171 patients screened, 53 patients presenting a known neoplasic thyroid disease were excluded.
(C) 2017 The authors Published by Bioscientifica Ltd

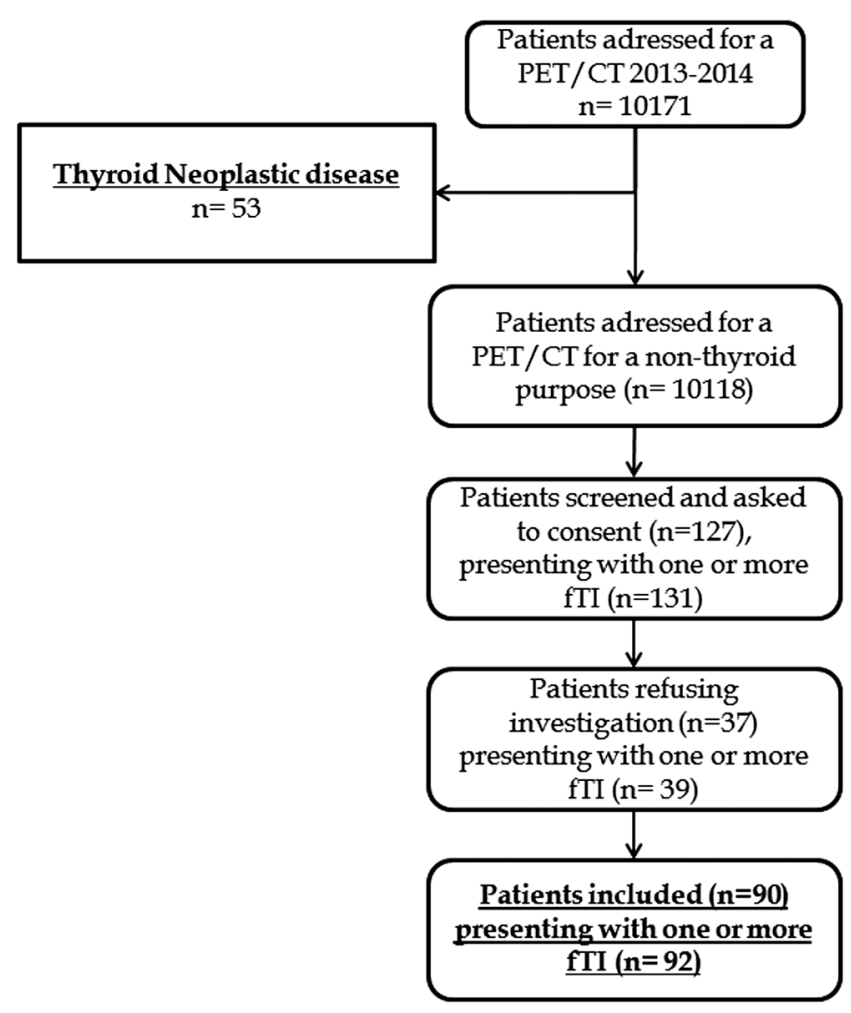

Figure 1

Flowchart selection of fTI in our study.

Among the remaining 10,118 patients, 127 patients who presented one or more fTI (corresponding to a total number of $131 \mathrm{fTI}$ ) were asked to consent to inclusion in the study. Ninety patients with 92 fTI agreed to participate and were explored by US (31 patients by only US and 59 by US and FNAB). Figure 1 displays the study flowchart.

Population characteristics are described in the Table 1 . Mean age was $64.2 \pm 11.6$ years. Regarding study of thyroid cancer risk factors in our cohort, 48 of the 90 patients were aged $>65$ years, 35 of the 90 patients were male.

\section{Follow-up}

Among the 92 fTI included in the cohort and who benefited from a US \pm FNAB, 26 had a surgical indication: 25 with an immediate theoretical indication (23 related to the suspicious nature of the fTI, 1 Graves' disease relapse and 1 for a voluminous goiter) and 1 during the systematical follow-up showing a significant fTI growth. Among these 26 fTI with surgical indication, 7 could not be operated: 6 due to a surgical contra-indication regarding patient history (recurrent laryngeal paralysis $(n=1)$, severe chronic cardiac and respiratory disease http://www.endocrineconnections.org DOI: 10.1530/EC-17-0099 
Table 1 Clinical characteristics and FDG PET-CT data.

\begin{tabular}{lcc}
\hline Characteristics & & Value $(n=90)$ \\
\cline { 1 - 2 } \pm s.D.) & & $64.2 \pm 11.6$ \\
Sex (male/female) & $45 / 55$ \\
FDG PET-CT purpose, $n$ & \\
$\quad$ Initial evaluation of a proven neoplasia & & 22 \\
$\quad$ Follow-up of a proven neoplasia & 27 \\
$\quad$ Suspicion of neoplasia & 15 \\
$\quad$ Suspicion of neoplasia recurrence & 6 \\
$\quad$ Research of primitive location & 5 \\
$\quad$ Other reasons & 15 \\
FDG PET-CT neoplastic disease activity, $n$ & \\
$\quad$ Certain & & 40 \\
$\quad$ Possible or absent & 50 \\
FDG PET-CT metastatic disease, $n$ & \\
$\quad$ Certain & 31 \\
Possible or absent & 59 \\
\hline
\end{tabular}

$(n=1)$, severe coronary artery disease $(n=1)$ and advanced neoplastic disease $(n=3))$ and 1 due to the patient's refusal $(n=1)$.

Forty-nine fTI were offered a systematic monitoring. Among these 49 fTI, 15 underwent at least one second US during follow-up (mean duration of follow-up $=12.9 \pm 3.8$ months). Finally, 5 had decreased in size, 9 remained stable and 1 increased in size.

An abstention was proposed for the last 17 remaining fTI.

\section{Imaging results}

In FDG PET-CT, fTI presented a median SUVmax value of 6.4 (interquartile (4.2-11.0)).

Sixty fTI benefited from an US associated with a FNAB (US $\pm \mathrm{FNAB}+$ subgroup). In this fTI subgroup, abstention was proposed for 6, monitoring for 30 and surgical indication for 24. Details of fTI care according to FNAB results are shown in Fig. 2

Thirty-two fTI in 31 patients benefited from a neck US without FNAB (US \pm FNAB-subgroup). FNAB was not performed by impossibility in 9 cases ( 2 patients refusal, 2 patients treated by oral anticoagulant at the time of US and 5 patients who presented an inaccessible fTI to FNAB) or by the absence of US indication in 22 cases ( 1 with size $<7 \mathrm{~mm}, 19$ without nodule or typical pseudonodular aspect and 2 benefiting from a surgical indication for another reason).

\section{US characteristics of fTI in our cohort}

US characteristics of fTI are detailed in Table 2. Eighty fTI correspond to a true node aspect on US and 5 to a typical aspect of pseudonodular thyroiditis. In the remaining 7 cases, no concordant nodule with fTI was found sonographically. Regarding the 4 major criteria of

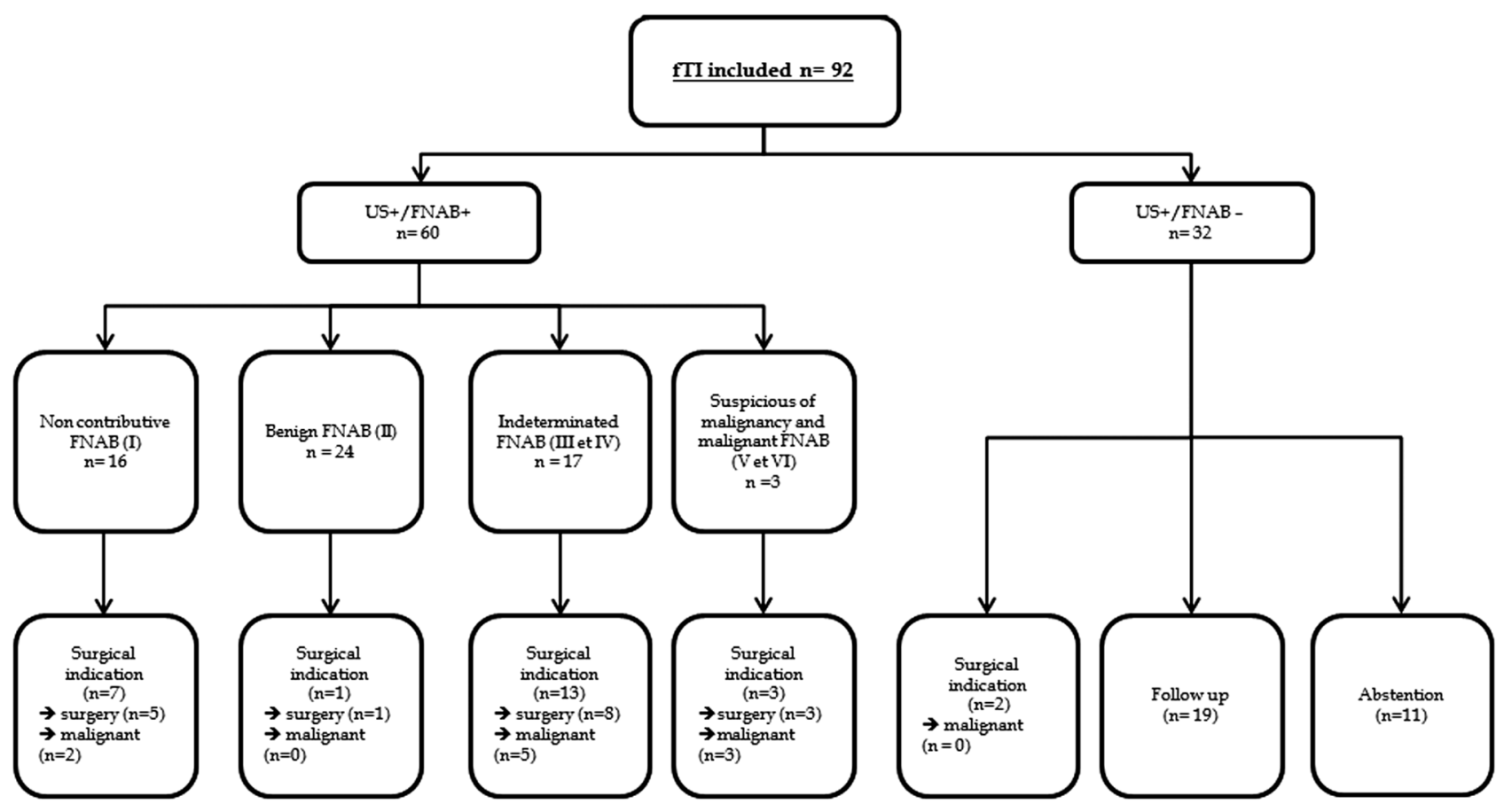

Figure 2

fTI care in patients of US $\pm F N A B-$ subgroup and US $\pm F N A B+$ subgroup according to FNAB results.

\begin{tabular}{|c|c|}
\hline $\begin{array}{l}\text { http://www.endocrineconnections.org } \\
\text { DOI: } 10.1530 / \text { EC-17-0099 }\end{array}$ & $\begin{array}{r}\text { (c) } 2017 \text { The authors } \\
\text { Published by Bioscientifica Ltd }\end{array}$ \\
\hline
\end{tabular}


Table 2 Ultrasonographical aspect and TIRADS classification of fTI in our cohort.

\begin{tabular}{|c|c|}
\hline Characteristics of fTI $(n=92)$ & Value \\
\hline \multicolumn{2}{|l|}{ Node $(n=92)$} \\
\hline Present & 80 \\
\hline Absent & 7 \\
\hline Typical pseudonodular aspect & 5 \\
\hline Largest diameter in $\mathrm{mm}($ mean \pm S.D. $)(n=78)$ & $15.34 \pm 9.05$ \\
\hline Volume in $\mathrm{cm}^{3}($ mean \pm s.D. $)(n=70)$ & $3.07 \pm 6.7$ \\
\hline \multicolumn{2}{|l|}{ Localization $(n=80)$} \\
\hline Left & 33 \\
\hline Right & 46 \\
\hline Purely isthmic & 1 \\
\hline \multicolumn{2}{|l|}{ US structure $(n=73)$} \\
\hline Cystic & 1 \\
\hline Solid & 34 \\
\hline Mixed predominantly solid & 38 \\
\hline Mixed predominantly cystic & 0 \\
\hline \multicolumn{2}{|l|}{ Echogenicity $(n=80)$} \\
\hline Marked hypoechogenicity & 3 \\
\hline Hypoechoic & 36 \\
\hline Isoechoic & 36 \\
\hline Hyperechoic & 3 \\
\hline Sides entirely calcified & 2 \\
\hline \multicolumn{2}{|l|}{ Margins $(n=77)$} \\
\hline Regular & 67 \\
\hline Irregular & 10 \\
\hline \multicolumn{2}{|l|}{ More tall than wide $(n=77)$} \\
\hline Yes & 4 \\
\hline No & 73 \\
\hline \multicolumn{2}{|l|}{ Macrocalcification(s) $(n=78)$} \\
\hline Present & 12 \\
\hline Absent & 66 \\
\hline \multicolumn{2}{|l|}{ Microcalcification(s) $(n=78)$} \\
\hline Present & 11 \\
\hline Absent & 67 \\
\hline \multicolumn{2}{|l|}{ Vascularization $(n=72)$} \\
\hline Absent & 6 \\
\hline Peripherical or predominantly peripheric & 30 \\
\hline $\begin{array}{l}\text { Predominantly intranodular, intranodular } \\
\text { or diffuse }\end{array}$ & 36 \\
\hline \multicolumn{2}{|l|}{ TIRADS $(n=85) *$} \\
\hline 2 & 7 \\
\hline 3 & 31 \\
\hline $4 \mathrm{~A}$ & 28 \\
\hline 4B & 19 \\
\hline 5 & 0 \\
\hline
\end{tabular}

$\star 80+5$ typical pseudonodular aspect.

malignancy, fTI presented a marked hypoechogenicity in 3 cases, irregular margins in 10 cases, microcalcifications in 11 cases and a taller-than-wide shape in 4 cases. No fTI was classified as TIRADS 5, whereas 19 were classified as TIRADS 4B.

\section{Cytological characteristics of $\mathrm{fTI}$ in our cohort}

Cytological results in 60 FNAB concluded as follows: 16 as nondiagnostic or unsatisfactory, 24 as benign, 5 as
AUS/FLUS, 12 as FNS/SFN, 1 as suspicious for malignancy and 2 as malignant. In class II cytology, 4 corresponded to a cytological aspect of thyroiditis.

\section{Surgical outcomes and predictive factor of malignancy}

Surgical outcomes Nineteen fTI have finally been operated and 10 were diagnosed as malignant lesions histologically proven in light to $\mathrm{US}_{ \pm} \mathrm{FNAB}+$ group $(n=60)$ and the whole population $(n=92)$. Histological nature of lesion was as follows: papillary thyroid carcinoma $(n=6)$, follicular thyroid carcinoma $(n=3)$ and intra-thyroid metastasis $(n=2)$ of 1 renal cell carcinoma and 1 nonsmall-cell lung primary cancer. One fTI revealed to be a vesicular poorly differentiated carcinoma associated with micro-metastatic foci of a non-small-cell lung cancer located inside the thyroid carcinoma. One-third of the 9 primary thyroid cancers had a histological pattern with a pejorative prognosis: 1 tall cell variant of papillary thyroid cancer, 1 vesicular poorly differentiated carcinoma and 1 Hurtle cell carcinoma.

Among the 9 benign results, 7 corresponded to a follicular lesion (including 2 hurtle cell adenomas), 1 to a dystrophic goiter and 1 to a Grave's disease histological pattern.

\section{Comparison between benign and malignant fTI} groups Comparison between benign and malign fTI groups is detailed in Table 3.

According to the available cytological and histological data, 41 of the 92 fTI could be classified as benign or malignant.

No clinical criteria were significantly associated with malignancy in our population. Median SUVmax was higher in malignant (10.4 (4.5-12.9)) than that in benign (6.4 (5.1-12.9)) fTI groups without significance $(P=0.649)$. Proportion of patients aged 65 years or older was similar in benign and malignant fTI, respectively $(P=0.75)$. Male gender was more represented in malignant than in benign fTI groups but without significance as well $(P=0.064)$.

Malignant fTI presented more often marked hypoechogenicity, irregular margins, 'more tall than wide shape' and microcalcification than benign fTI, but results were not statistically significant. Proportion of FNAB indication according to Kim criteria was significantly higher in malignant than that in benign fTI $(P=0.006)$.

Comparison between the results of the TIRADS classification with histological and cytological data

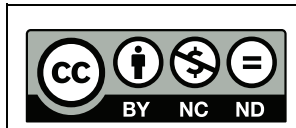

This work is licensed under a Creative Commons Attribution-NonCommercial-NoDerivatives 4.0 International License. 
Table 3 Comparison between benign and malign fTI groups.

\begin{tabular}{|c|c|c|c|}
\hline US characteristics & $\begin{array}{c}\text { Benign } \\
(n=31)\end{array}$ & $\begin{array}{l}\text { Malignant } \\
\quad(n=10)\end{array}$ & $P$ value \\
\hline Size (mm; mean \pm s.D.) & $\overline{17.2 \pm 7.1}$ & $\overline{20.0 \pm 16.4}$ & 0.619 \\
\hline Hypoechogenicity (n) & 15 & 8 & 0.145 \\
\hline Marked hypoechogenicity $(n)$ & 1 & 2 & 0.149 \\
\hline Irregular margins $(n)$ & 3 & 3 & 0.163 \\
\hline More tall than wide $(n)$ & 1 & 2 & 0.156 \\
\hline Microcalcification(s) (n) & 4 & 2 & 0.29 \\
\hline Kim criteria* $(n)$ & 4 & 6 & 0.006 \\
\hline $\operatorname{TIRADS} \geq 4 \mathrm{~A} *(n)$ & 10 & 9 & 0.238 \\
\hline FES guidelines* $(n)$ & 17 & 6 & 0.775 \\
\hline
\end{tabular}

*Proportion of FNAB indication according to each US classification.

available is detailed in Table 4. One malignant fTI was classified TIRADS 3,3 as TIRADS $4 \mathrm{~A}$ and 6 as TIRADS 4B.

\section{Discussion}

Our study performed on a large population of unselected patients, found a prevalence of $1.3 \%$ of fTI. Among the 60 fTI explored by US and FNAB, 10 were found to be malignant. We analyzed a wide population of 10,171 FDG PET-CT in a region of about 1 million habitants with only one nuclear medicine department equipped with a PET-CT system. To our knowledge, this is one of the few studies assessing prospective prevalence and malignancy rate of fTI (6). Exploration rate was high because more than $70 \%$ of our patients underwent at least one US and $46 \%$ underwent an US+FNAB. Among the $60 \mathrm{fTI}$ in this $\mathrm{US}+\mathrm{FNAB}+$ group, 10 were found to be malignant with a usual prevalence of papillary and follicular thyroid carcinoma (12).

In this series, we decided to explore only fTI. Indeed, focal (fTI) and diffuse (dTI) patterns of FDG thyroid uptake do not have the same significance. Kang and coworkers showed that the exploration of dTI by cervical ultrasound revealed a thyroid nodule in only $59.5 \%$ of patients while more than $99.0 \%$ of patients with fTI effectively showed a thyroid node (13). Moreover, several studies showed that dTI is essentially related to an inflammatory disease of the

Table 4 Correlation between TIRADS classification and cytological/histological data.

\begin{tabular}{|c|c|c|c|}
\hline TIRADS $(n=62)$ & Benign & $\begin{array}{l}\text { Undeterminate } \\
\text { (FNAB 1, } 3 \text { and } 4 \text { ) }\end{array}$ & Malignant \\
\hline $2(n=3)$ & 1 & 2 & 0 \\
\hline $3(n=20)$ & 13 & 6 & 1 \\
\hline $4 \mathrm{~A}(n=21)$ & 13 & 5 & 3 \\
\hline 4B $(n=18)$ & 4 & 8 & 6 \\
\hline $5(n=0)$ & 0 & 0 & 0 \\
\hline
\end{tabular}

Docrineconnections.org DOI: 10.1530/EC-17-0099 thyroid, such as thyroiditis or more rarely Graves' disease $(14,15)$. A recent meta-analysis also highlighted a low malignancy risk of $4.4 \%$ in dTI (4).

In our cohort, the prevalence of fTI is $1.3 \%$. It remains slightly lower than the prevalence reported in two different meta-analyses conducted by Soelberg and coworkers and Bertagna and coworkers (1.6 and 2.5\%, respectively) $(4,5)$. Nevertheless, our result is in accordance with previous studies reporting a prevalence ranging from 0.2 to $8.6 \%$ $(16,17)$. In our opinion, this large gap demonstrates the heterogeneity of the population that is limited in our series because of its prospective nature and the systematic notification of fTI.

The malignancy rate in our study is also lower than the rates observed in the literature. Thus, only 10 of the 60 nodules explored by US + FNAB and/or surgery in our cohort had a confirmed malignant thyroid disease, while malignancy rates reported in meta-analysis range from $19.8 \%$ to $36.2 \%(4,5,18,19)$. Several hypotheses may explain this difference. Firstly, 7 of our 26 patients had surgical indication but could not be operated. This can lead to an underestimation of the prevalence of malignant fTI in our cohort. Another hypothesis is the retrospective nature of currently available studies, which led to selection bias and probably increases the prevalence of malignant lesions (18). Indeed, only the most suspicious lesions were explored and benefited from a $\mathrm{FNAB} \pm$ surgery. In their meta-analysis, Treglia and coworkers highlighted that only a limited proportion of fTI detected by FDG PET or FDG PET/CT underwent cytology or histology confirmation. Therefore, the calculation of malignancy rate, based on cytological and pathology data only, did not consider all the fTI and this may represent a selection bias (18).

Regarding cytological data, a large proportion of fTI in our cohort presented a non-contributive cytology (16/60) and indeterminate cytology (17/60). These proportions are higher than the results expected according to the Bethesda classification: $<10 \%$ and nearly $20 \%$ for noncontributive and indeterminate (III/IV) cytologies, respectively (20). These high proportions may explain why we found only 24 benign cytologies in our study. Finally, 4 of the 24 benign fTI corresponded to a cytological aspect of thyroiditis. Thus, thyroiditis may also induce fTI and not only dTI. A recent study demonstrated that 2 of the 31 fTI described in FDG PET/CT showed a focal aspect of Hashimoto's thyroiditis (21).

No predictor of malignancy was found in our cohort, despite a strict gold standard for comparison of benign and malignant ITF (excluding lesions with indeterminate or non-contributive cytology's (classes 1, 3 and 4)). 
SUVmax values in FDG PET-CT were not significantly associated with a higher malignancy rate. However, SUVmax is a semi-quantitative parameter that reflects metabolic activity but not specifically malignant nature. For fTI, the usefulness of SUVmax to distinguish benign from malignant lesions has been proven in many studies $(22,23,24)$ and reviewed in several meta-analysis $(4,5)$. However, no safe cut-off has been identified. Indeed, many benign lesions could present a high FDG avidity such as Hurthle cell adenomas $(5,25)$ probably because of their high number of mitochondria (26). In a recent review, Bertagna and coworkers highlighted that approximately half of the papers reported a statistically difference between SUVmax of benign and malignant lesions, whereas the other showed the opposite (5). Our results are then consistent with literature with a nonsignificant slightly higher median SUVmax in malignant than in benign fTI.

Neckultrasound (US) has become the referenceimaging for exploration of thyroid nodules. Many authors have assessed US characteristics of thyroid nodules to predict malignancy. Several classifications have therefore been established and evaluated according to their performance to predict whether a nodule is malignant and benign. Kim criteria are the oldest, based on the presence of at least one of 4 major criteria (marked hypoechogenicity, more tall than wide shape, irregular margin and presence of microcalcifications) to characterize a nodule as malignant (8). More recently, the TIRADS score has been developed to propose a classification of the nodule in several categories ranging from TIRADS 2-5, corresponding to a probability of malignancy (low risk of malignancy for TIRADS 4A and high risk of malignancy for TIRADS 4B and 5) (9). According to TIRADS score and the nodule size, Russ and coworkers proposed to perform or not a FNAB (9). For fTI, the French Society of Endocrinology consensus recommended as for it to perform a FNAB in case of nodule size $\geq 7 \mathrm{~mm}$ (7). More recently, American Thyroid Association recommended a clinical evaluation and to perform a FNAB in case of nodule size $\geq 10 \mathrm{~mm}$ (27).

Literature is rich about the usefulness of ultrasonography to explore thyroid nodules. Paradoxically, studies that specifically assessed US performance for malignancy prediction in fTI are rare. Kwak and coworkers assessed 87 fTI by US using the 4 Kim criteria and the thyroid nodule was classified as 'suspicion of malignancy' or 'probably benign' (28). In their cohort, the rate of malignancy was high estimated as $48.3 \%$. US performance showed a sensitivity of $88 \%$ and a specificity of $73 \%$ to predict malignancy. Authors suggested that US remained useful and provide a better characterization of nodules. In a recent retrospective study assessing 66 fTI by using TIRADS score in US. Most of the thyroid nodules were scored $4 \mathrm{~A}$. Thereby, 30 percent (20/66) of fTI were considered as malignant with 4, 9 and 7 nodules ranged TIRADS 4A, 4B and 5, respectively. Moreover, no fTI were ranged TIRADS 2 or 3 . Then, the authors concluded that TIRADS score remains valid for the study of fTI (29).

In our study, proportion of FNAB indication according to Kim criteria was significantly higher in malignant than that in benign fTI $(P=0.006)$. This association was not showed for FES Guidelines or TIRADS classifications. Indeed, for TIRADS classification, 10 of the 31 benign fTI had an FNAB indication in our cohort. This point could be explained by the large proportion of thyroid nodules classified TIRADS 4A in our cohort suggesting a low specificity of malignancy. This large proportion of TIRADS $4 \mathrm{~A}$ thyroid node (45\%) was also retrieved in the study by Dierick-Gallet and coworkers (29).

Our study has several limitations. Firstly, it is a singlecenter study including only Caucasian population that does not allow extending our results to other ethnicity. Secondly, a substantial proportion of patients refused US, and this point may be a selection bias. Finally, although the study was conducted on a very large population, the unexpected low prevalence of fTI in our cohort (1.3\%), the small effective of fTI responding to the gold standard $(n=41)$ and the low malignancy rate, induced a very low statistical power for assessing a potential predictive of malignancy criteria of fTI.

\section{Conclusion}

In conclusion, our study is to our knowledge one of the few prospective studies assessing the prevalence and malignancy rate of fTI. We found a prevalence of $1.3 \%$ in our cohort that appears compatible with those described previously in the literature but with a malignancy rate of $16.6 \%$ lower than that published in recent metaanalyses. Medical care of fTI remains complex and is firstly dependent on the patient's clinical history and its neoplastic pathology. The couple neck US + FNAB remains essential in fTI care although US classifications used seem less discriminating in this specific situation.

\section{Declaration of interest}

The authors declare that there is no conflict of interest that could be perceived as prejudicing the impartiality of the research reported. 
Funding

This research did not receive any specific grant from any funding agency in the public, commercial or not-for-profit sector.

\section{Acknowledgments}

V K and P Y S are the guarantors of the paper. P T, N R and P Y S designed the study. $P T$ realized statistics. $P$ T drafted the manuscript. $P T, N R$, G C, M C and P R analyzed the data. N R, V K, P Y S and R A revised the manuscript. All authors contributed in drawing up the manuscript.

\section{References}

1 Steele SR, Martin MJ, Mullenix PS, Azarow KS \& Andersen CA. The significance of incidental thyroid abnormalities identified during carotid duplex ultrasonography. Archives of Surgery 2005140 981-985. (doi:10.1001/archsurg.140.10.981)

2 Youserm DM, Huang T, Loevner LA \& Langlotz CP. Clinical and economic impact of incidental thyroid lesions found with CT and MR. American Journal of Neuroradiology 199718 1423-1428.

3 Yoon DY, Chang SK, Choi CS, Yun EJ, Seo YL, Nam ES, Cho SJ, Rho Y-S \& Ahn HY. The prevalence and significance of incidental thyroid nodules identified on computed tomography. Journal of Computer Assisted Tomography 200832 810-815. (doi:10.1097/ RCT.0b013e318157fd38)

4 Soelberg KK, Bonnema SJ, Brix TH \& Hegedüs L. Risk of malignancy in thyroid incidentalomas detected by ${ }^{18} \mathrm{~F}$-Fluorodeoxyglucose positron emission tomography: a systematic review. Thyroid $2012 \mathbf{2 2}$ 918-925. (doi:10.1089/thy.2012.0005)

5 Bertagna F, Treglia G, Piccardo A \& Giubbini R. Diagnostic and clinical significance of F-18-FDG-PET/CT thyroid incidentalomas. Journal of Clinical Endocrinology and Metabolism 201297 3866-3875. (doi:10.1210/jc.2012-2390)

6 Ohba K, Nishizawa S, Matsushita A, Inubushi M, Nagayama K, Iwaki H, Matsunaga H, Suzuki S, Sasaki S \& Oki Y. High incidence of thyroid cancer in focal thyroid incidentaloma detected by 18F-fluorodexyglucose positron emission tomography in relatively young healthy subjects: results of 3-year follow-up. Endocrine Journal 201057 395. (doi:10.1507/endocrj.K10E-008)

7 Wémeau J-L, Sadoul J-L, d'Herbomez M, Monpeyssen H, Tramalloni J, Leteurtre E, Borson-Chazot F, Caron P, Carnaille B, Léger J, et al. Guidelines of the French society of endocrinology for the management of thyroid nodules. Annals of Endocrinology 201172 251-281. (doi:10.1016/j.ando.2011.05.003)

8 Kim E-K, Park CS, Chung WY, Oh KK, Kim DI, Lee JT \& Yoo HS. New sonographic criteria for recommending fine-needle aspiration biopsy of nonpalpable solid nodules of the thyroid. American Journal of Roentgenology 2002178 687-691. (doi:10.2214/ajr.178.3.1780687)

9 Russ G, Royer B, Bigorgne C, Rouxel A, Bienvenu-Perrard M \& Leenhardt L. Prospective evaluation of thyroid imaging reporting and data system on 4550 nodules with and without elastography. European Journal of Endocrinology 2013168 649-655. (doi:10.1530/EJE-12-0936)

10 Theoharis CG, Schofield KM, Hammers L, Udelsman R \& Chhieng DC. The Bethesda thyroid fine-needle aspiration classification system: year 1 at an academic institution. Thyroid 2009 19 1215-1223. (doi:10.1089/thy.2009.0155)

11 Edge SB, Byrd DR, Compton CC, Fritz AG, Greene FL \& Trotti A. In AJCC Cancer Staging Manual, 7th ed. New York, NY, USA: Springer-Verlag, 2010.

12 Schlumberger MJ. Papillary and follicular thyroid carcinoma. New England Journal of Medicine 1998338 297-306. (doi:10.1056/ NEJM199801293380506)

13 Kang BJ, O JH, Baik JH, Jung SL, Park YH \& Chung SK. Incidental thyroid uptake on F-18 FDG PET/CT: correlation with ultrasonography and pathology. Annals of Nuclear Medicine 200923 729-737. (doi:10.1007/s12149-009-0299-4)

14 Kurata S, Ishibashi M, Hiromatsu Y, Kaida H, Miyake I, Uchida M \& Hayabuchi N. Diffuse and diffuse-plus-focal uptake in the thyroid gland identified by using FDG-PET: prevalence of thyroid cancer and Hashimoto's thyroiditis. Annals of Nuclear Medicine 200721 325-330. (doi:10.1007/s12149-007-0030-2)

15 Lee JY, Choi JY, Choi Y-H, Hyun SH, Moon SH, Jang SJ, Choe YS, Lee K-H \& Kim B-T. Diffuse thyroid uptake incidentally found on ${ }^{18} \mathrm{~F}$-Fluorodeoxyglucose positron emission tomography in subjects without cancer history. Korean Journal of Radiology 201314501. (doi:10.3348/kjr.2013.14.3.501)

16 Bae J, Chae B, Park W, Kim J, Kim S, Jung S \& Song B. Incidental thyroid lesions detected by FDG-PET/CT: prevalence and risk of thyroid cancer. World Journal of Surgical Oncology 2009763. (doi:10.1186/1477-7819-7-63)

17 King D, Stackjr B, Spring P, Walker R \& Bodenner D. Incidence of thyroid carcinoma in fluorodeoxyglucose positron emission tomography-positive thyroid incidentalomas. Otolaryngology: Head and Neck Surgery 2007137 400-404. (doi:10.1016/ j.otohns.2007.02.037)

18 Treglia G, Bertagna F, Sadeghi R, Verburg FA, Ceriani L \& Giovanella L. Focal thyroid incidental uptake detected by $18 \mathrm{~F}$-fluorodeoxyglucose positron emission tomography: meta-analysis on prevalence and malignancy risk. Nuklearmedizin 201352 130-136. (doi:10.3413/ Nukmed-0568-13-03)

19 Nayan S, Ramakrishna J \& Gupta MK. The proportion of malignancy in incidental thyroid lesions on 18-FDG PET study: a systematic review and meta-analysis. Otolaryngology: Head and Neck Surgery 2014151 190-200. (doi:10.1177/0194599814530861)

20 Bongiovanni M, Spitale A, Faquin WC, Mazzucchelli L \& Baloch ZW. The Bethesda system for reporting thyroid cytopathology: a metaanalysis. Acta Cytologica 201256 333-339. (doi:10.1159/000339959)

21 Jamsek J, Zagar I, Gaberscek S \& Grmek M. Thyroid lesions incidentally detected by 18F-FDG PET-CT - a two centre retrospective study. Radiology and Oncology 201549 121-127. (doi:10.2478/raon2014-0039)

22 Choi JY, Lee KS, Kim H-J, Shim YM, Kwon OJ, Park K, Baek C-H, Chung JH Lee K-H \& Kim B-T. Focal thyroid lesions incidentally identified by integrated 18F-FDG PET/CT: clinical significance and improved characterization. Journal of Nuclear Medicine 200647 609-615.

23 Pagano L, Samà MT, Morani F, Prodam F, Rudoni M, Boldorini R, Valente G, Marzullo P, Baldelli R, Appetecchia M, et al. Thyroid incidentaloma identified by $18 \mathrm{~F}$-fluorodeoxyglucose positron emission tomography with CT (FDG-PET/CT): clinical and pathological relevance: Thyroid incidentaloma. Clinical Endocrinology 201175 528-534. (doi:10.1111/j.1365-2265.2011.04107.x)

24 Pampaloni MH \& Win AZ. Prevalence and characteristics of incidentalomas discovered by whole body FDG PETCT. International Journal of Molecular Imaging 20122012 e476763. (doi:10.1155/2012/476763)

25 Kresnik E, Gallowitsch HJ, Mikosch P, Stettner H, Igerc I, Gomez I, Kumnig G \& Lind P. Fluorine-18-fluorodeoxyglucose positron emission tomography in the preoperative assessment of thyroid nodules in an endemic goiter area. Surgery 2003133 294-299. (doi:10.1067/msy.2003.71)

26 Sobrinho-Simões MA, Nesland JM, Holm R, Sambade MC \& Johannessen JV. Hürthle cell and mitochondrion-rich papillary carcinomas of the thyroid gland: an ultrastructural and immunocytochemical study. Ultrastructural Pathology 19858 131-142.

27 Haugen BR, Alexander EK, Bible KC, Doherty GM, Mandel SJ, Nikiforov YE, Pacini F, Randolph GW, Sawka AM, Schlumberger M, et al. 2015 American Thyroid Association Management Guidelines for adult patients with thyroid nodules and differentiated thyroid cancer: the American Thyroid Association Guidelines Task Force on Thyroid 
Nodules and Differentiated Thyroid Cancer. Thyroid 201626 1-133. (doi:10.1089/thy.2015.0020)

28 Kwak JY, Kim E-K, Yun M, Cho A, Kim MJ, Son EJ \& Oh KK. Thyroid incidentalomas identified by ${ }^{18} \mathrm{~F}$-FDG PET: sonographic correlation. American Journal of Roentgenology 2008191 598-603. (doi:10.2214/ AJR.07.3443)
29 Dierick-Gallet A, Borget I, Lepoutre C, Vielh P, Alghuzlan A, Hartl D, Berdelou A, Girard E, Deandreis D, et al. Poster P1-051: Incidentalomes thyroïdiens fixant le FDG: prise en compte des critères échographiques de suspicion de malignité dans les indications de cytoponction. Annales d'Endocrinologie 201475 319. (doi:10.1016/ j.ando.2014.07.171)

Received in final form 14 June 2017

Accepted 22 June 2017

Accepted Preprint published online 22 June 2017
This work is licensed under a Creative Commons Attribution-NonCommercial-NoDerivatives 4.0 International License. 